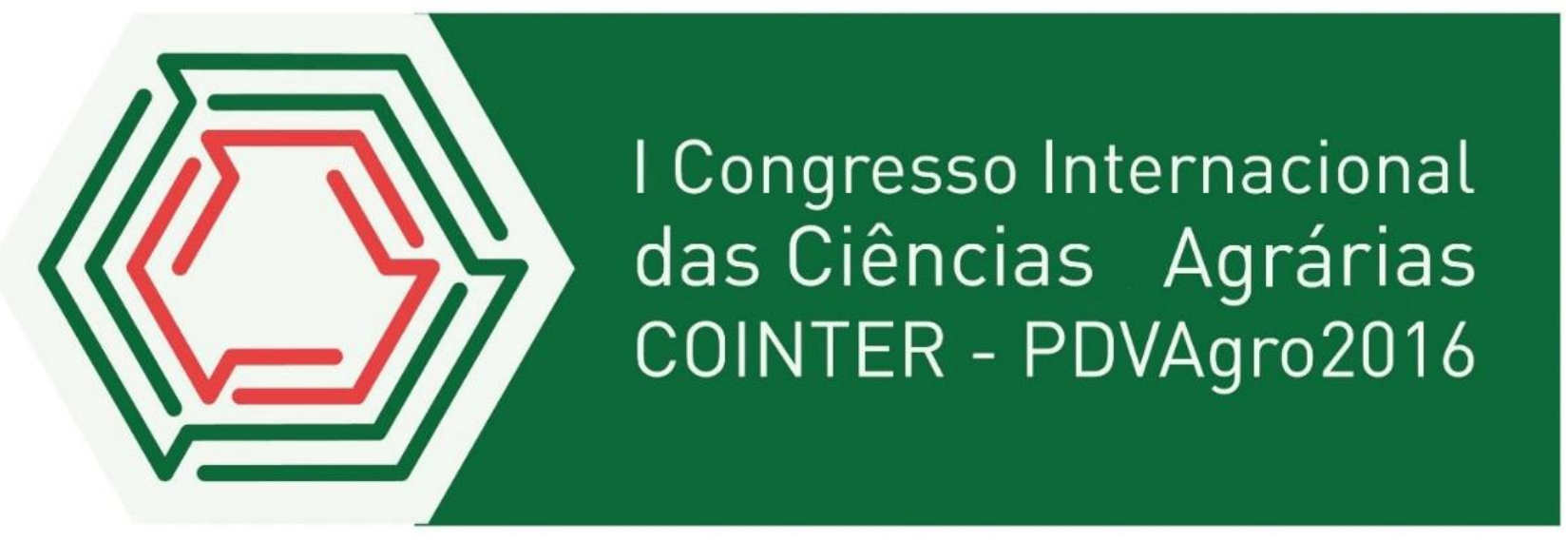

\title{
CARBONO E NITROGÊNIO NA SERAPILHEIRA ACUMULADA EM FRAGMENTOS DE CAATINGA NA PARAÍBA
}

\author{
Apresentação: Pôster
}

Paulo César Alves do Ó ${ }^{1}$; José Reybson Nicácio de Sousa²; Suellen Cristina Pantoja Gomes ${ }^{3}$; Alana Ventura Ferreira ${ }^{4}$; Ane Cristine Fortes da Silva ${ }^{5}$

\section{Introdução}

O processo de ciclagem de nutrientes exerce importante papel na produção de florestal. Por esta razão, é relevante entender as interações solo-floresta como a produção e o acúmulo de serapilheira para a manutenção da sustentabilidade florestal.

Estudos sobre a quantificação de serapilheira acumulada contribuem para melhor compreender a dinâmica dos nutrientes, isto é, por meio da quantidade e qualidade da serapilheira produzida, possibilitando então informações que auxiliem na escolha de espécies para a formação de maciços florestais (CALDEIRA et al., 2009).

São escassos, na literatura, os estudos sobre a qualidade e quantidade da serapilheira em particular em áreas de Caatinga sob processo de recuperação e em áreas degradadas. Estas informações podem auxiliar na formulação e avaliação de estratégias de manejo que promovam o uso sustentável desse bioma.

Desta forma, a presente pesquisa justifica-se em virtude da insuficiência de estudos e práticas inseridos nesta temática e a relevância de estudos fundamentados cientificamente objetivando conhecimento a respeito da qualidade do solo em diferentes áreas de regeneração, tratando-a aqui de um bem natural utilizado na dinâmica do ecossistema terrestre.

\footnotetext{
${ }^{1}$ Tecnologia em Gestão Ambiental - “Bolsista do PIBICT - IFPB”, Instituto Federal da Paraíba, pcalvesdoo@gmail.com

${ }^{2}$ Gestora Ambiental, Instituto Federal da Paraíba, alana-ventura12@hotmail.com

${ }^{3}$ Mestrado em Ciências Florestais, Universidade Federal Rural de Pernambuco, eng.suellengomes@yahoo.com.br

${ }^{4}$ Gestor Ambiental, Engenharia Florestal, Universidade Federal de Campina Grande, reybson.sousa@hotmail.com ${ }^{5}$ Doutoranda em Ciências Florestais, Universidade Federal Rural de Pernambuco, Professora do Instituto Federal da Paraíba, ane.silva@ifpb.edu.br
} 
Diante da relevância de estudos sobre os nutrientes contidos na serapilheira acumulada, o presente trabalho teve como objetivo avaliar a relação entre o carbono e nitrogênio na serapilheira estocada no solo sob vegetação Caatinga.

\section{Fundamentação Teórica}

A compreensão da interação entre a floresta e o solo, principalmente da matéria orgânica formada através dessa relação, vem sendo amplamente estudada como ferramenta para a conservação do solo florestal (CONCEIÇÃO et al., 2005). A matéria orgânica do solo (MOS) apresenta relevante papel na regulação da sustentabilidade florestal, referindo-se a todo material orgânico depositado no solo na forma de resíduos vegetais, biomassa microbiana, meso e macrofauna. (BARRETO, 2014), e estão atreladas diretamente ao material vegetal ou serapilheira que está sendo depositada no solo.

A compreensão da dinâmica da MOS proporciona o entendimento dos processos de decomposição e deposição do carbono e nutrientes no solo. Devido à atividade biológica o solo passa a conter carbono e nitrogênio, dois importantes elementos não existentes em sua origem, fazendo com que a matéria orgânica configure-se como uma importante fonte desses elementos (BALBINOT, 2009).

A contribuição de matéria orgânica formada por galhos, cascas, folhas que compõem a serapilheira são influenciadas pela idade da floresta (BARRETO et al., 2008). A quantidade de nutriente existente na serapilheira depende de alguns fatores, como a espécie, o solo, a capacidade de redistribuição de nutrientes antes da senescência, da proporção de folhas em relação aos demais componentes (SCHUMACHER, 1992).

\section{Metodologia}

O estudo foi desenvolvido em três áreas experimentais situadas no interior do Instituto de Educação, Ciência e Tecnologia da Paraíba (IFPB), localizada no município de Princesa Isabel PB. O clima local, segundo a classificação de Köppen, é do tipo Aw', Tropical Quente e Úmido com chuvas de verão-outono. A topografia do terreno apresenta-se bastante ondulada e o solo é classificado como Latossolo vermelho. Os sítios experimentais foram fragmentos de Caatinga definidos conforme o tempo de regeneração no local, a saber: estágio secundário (ES), estágio inicial (EI) e área degradada (AD).

A coleta da serapilheira acumulada sob o solo nas áreas de estudo foi realizada no mês de março de 2016, com o auxílio de um gabarito de madeira em formato quadrangular $\left(0,0625 \mathrm{~m}^{2}\right)$. O 
gabarito, em campo, foi disposto aleatoriamente na superfície do terreno, seguindo a declividade do local, e os resíduos orgânicos circunscritos foram coletados e armazenados em sacolas de plástico. Esses materiais foram acondicionados em sacos de papel e transportados para o laboratório. Posteriormente, foi realizada a separação das folhas e galhos da serapilheira, antes da secagem em estufa a $65^{\circ} \mathrm{C}$ até peso constante para, então, se fazer a determinação da massa seca. As amostras foram trituradas em moinho tipo Wiley e analisadas para a determinação do teor do $\mathrm{N}$ e $\mathrm{C}$ total pela metodologia da EMBRAPA (2009).

\section{Resultados e Discussões}

A menor quantidade de serapilheira acumulada para fração folhas foi estimada para a área em estágio inicial de tempo de regeneração (EI). Já em relação à fração galhos a menor contribuição foi observada na área degradada (AD) (Tabela 1).

Tabela 1. Serapilheira acumulada média $\left(\mathrm{kg} \cdot \mathrm{ha}^{-1}\right)$ dividida nas frações folhas e galhos e relação C/N média.

\begin{tabular}{cccc}
\hline & \multicolumn{3}{c}{ Serapilheira acumulada média (kg.ha $^{-1}$ ) } \\
\cline { 2 - 4 } & Folhas & Galhos & $\begin{array}{c}\text { Relação } \\
\text { C/N }\end{array}$ \\
\hline ES & $1.847,04 \mathrm{a}$ & $3.294,86 \mathrm{a}$ & 28 \\
EI & $549,76 \mathrm{~b}$ & $1.229,76 \mathrm{~b}$ & 30 \\
AD & $696,18 \mathrm{~b}$ & $1.067,17 \mathrm{c}$ & 30 \\
\hline C.V. & 36,34 & 34,21 & 3,24
\end{tabular}

*Médias seguidas pela mesma letra na coluna não diferem entre si pelo teste de Scott-Knott a 5\% de probabilidade.

O maior acúmulo de serapilheira na área em estágio mais avançado pode ser resultado à maior biomassa acima do solo desta área, devido a maior preservação desta. Segundo Mateus et al. (2010), em ecossistemas degradados, a serapilheira acumulada traduz o fator contribuinte para a restauração, já que oferece condições mais favoráveis para o estabelecimento de espécies de níveis sucessionais mais avançados, permitindo o avanço da sucessão ecológica. Na tabela 1 também é possível verificar a relação $\mathrm{C} / \mathrm{N}$ média das áreas, em que a maior relação $\mathrm{C} / \mathrm{N}$ foi observada nas áreas mais degradadas, indicando maior tempo de decomposição da serapilheira quando em comparação com o estágio mais avançado.

De acordo com Cobo et al. (2002), baixos teores de nutrientes nos resíduos vegetais, geralmente, estão atreladas a baixas taxas de decomposição. Os materiais com elevada relação C/N (> 25) e altos teores de lignina e polifenóis são decompostos com velocidade menor (MYERS et al., 1994), o que favorece a manutenção dos resíduos orgânicos no solo, protegendo este, importante para a recuperação de áreas degradadas. O maior teor de nitrogênio e de carbono foi encontrado no 
estágio secundário em ambas as frações estudadas (Tabela 2).

Tabela 2. Teor médio de nitrogênio (N) e carbono (C) nas frações folhas e galhos da serapilheira acumulada.

\begin{tabular}{ccccc}
\hline & \multicolumn{2}{c}{$\mathbf{c} \mathbf{C}$} \\
\hline & Folhas & Galhos & Folhas & Galhos \\
ES & $16,00 \mathrm{a}^{*}$ & $375,97^{\mathrm{ns}}$ & $12,59^{\mathrm{ns}}$ & $391,07 \mathrm{a}$ \\
EI & $13,34 \mathrm{~b}$ & $359,40 \mathrm{n}$ & $11,95 \mathrm{x}$ & $376,77 \mathrm{c}$ \\
AD & $13,37 \mathrm{~b}$ & $375,57 \mathrm{~b}$ & $11,56 \mathrm{~b}$ & $381,21 \mathrm{~b}$ \\
\hline CV (\%) & 5,39 & 6,03 & 4,28 & 2,56 \\
\hline
\end{tabular}

*Médias seguidas pela mesma letra na coluna não diferem entre si pelo teste de Scott-Knott a 5\% de probabilidade.

Houve diferença estatística significativa para os teores de nitrogênio para a fração folhas e nas duas frações para o teor de carbono (Tabela 2). Esses teores contribuem para os incrementos nos estoques de $\mathrm{C}$ e $\mathrm{N}$, principalmente nas camadas mais superficiais do solo. Já em relação ao conteúdo médio de nitrogênio e de carbono da serapilheira acumulada (Tabela 3) houve diferença estatística significativa entre as áreas, sendo a maior quantidade estimada para o estágio secundário em todas as frações estudadas.

Tabela 3. Conteúdo médio de nitrogênio (N) e carbono (C) nas frações folhas e galhos da serapilheira acumulada.

\begin{tabular}{ccccc}
\hline & \multicolumn{2}{c}{$\mathbf{N}$} & \multicolumn{2}{c}{$\mathbf{C}$} \\
\hline & Folhas & Galhos & Folhas & Galhos \\
ES & $29,55 \mathrm{a}$ & $41,47 \mathrm{a}$ & $694,43 \mathrm{a}$ & $1.288,51 \mathrm{a}$ \\
EI & $7,34 \mathrm{c}$ & $13,92 \mathrm{~b}$ & $197,58 \mathrm{~b}$ & $463,33 \mathrm{~b}$ \\
AD & $9,31 \mathrm{~b}$ & $13,18 \mathrm{~b}$ & $261,46 \mathrm{~b}$ & $406,81 \mathrm{~b}$ \\
\hline CV (\%) & 7,83 & 6,98 & 6,43 & 11,76 \\
\hline
\end{tabular}

*Médias seguidas pela mesma letra na coluna não diferem entre si pelo teste de Scott-Knott a $5 \%$ de probabilidade.

$\mathrm{O}$ maior conteúdo de $\mathrm{N}$ e $\mathrm{C}$ no estágio secundário pode ser explicado parcialmente pela maior produção e acúmulo de serapilheira na área, o que resulta numa maior disponibilidade de nutrientes para a vegetação.

Os maiores conteúdos de $\mathrm{N}$ e C está alocada na fração galhos em todas as áreas avaliadas. Assim, o retorno de nutrientes ao solo tende a ser mais lento, já que a maioria da biomassa está alocada na madeira.

A degradação nas áreas levou a importantes modificações na dinâmica de nitrogênio e carbono nas áreas avaliadas, tendo os estágios mais avançados de regeneração apresentado os maiores conteúdos de nitrogênio e carbono, independente da fração avaliada.

Os dados aqui apresentados sustentam a hipótese de que os conteúdos médios de carbono e nitrogênio variam entre os estádios sucessionais no fragmento de Caatinga estudado. Os conteúdos 
médios de $\mathrm{N}$ e $\mathrm{C}$ diferem entre os tempos de regeneração, com incremento à medida que o tempo de sucessão avança.

\section{Conclusões}

A maior contribuição de serapilheira está relacionada a fração galhos nas áreas de Caatinga avaliada.

O teor e conteúdo de $\mathrm{N}$ e $\mathrm{C}$ decresce com o aumento do nível de degradação no fragmento de Caatinga estudado.

Estudo sobre as relações planta e solo, em diferentes tempos de sucessão na Caatinga, são necessários para contribuir para a compreensão dos processos de regeneração das florestas secas e assim subsidiar o manejo sustentável e conservação adequada destes ecossistemas.

\section{Agradecimentos}

Este trabalho foi realizado com apoio do Programa Institucional de Bolsas de Iniciação Cientifica e Tecnologia - IFPB, Campus Princesa Isabel.

\section{Referências}

BALBINOT, R. Carbono, Nitrogênio e Razões Isotópicas $\delta 13$ C e $\delta 15$ N no Solo e vegetação de Estágios Sucessionais de Floresta Ombrófila Densa Submontana. Tese [Doutorado em Ciências Agrárias] Programa de Pós Graduação em Engenharia Florestal, Curitiba: UFPR, 2009.

BARRETO, P. A. B; GAMA-RODRIGUES. E. F; GAMA-RODRIGUES, A. C; BARROS, N. F.; FONSECA, S. Atividade, carbono e nitrogênio da biomassa microbiana em plantações de eucalipto, em uma sequiência de idades. Revista Brasileira de Ciência do Solo, Viçosa, v. 32, n. 2, p. 611619, 2008.

BARRETO, P. A. B; GAMA-RODRIGUES, E. F; GAMA-RODRIGUES, A. C. Carbono das frações da matéria orgânica em solos sob plantações de eucalipto de diferentes idades. Sci. For., Piracicaba, v. 42, n. 104, p. 581-590, dez. 2014.

CALDEIRA, M. V. W; VITORINO, M. D; SCHAADT, S. S; MORAES, E; BALBINOT, R.Quantificação de serapilheira e de nutrientes em uma Floresta Ombrófila Densa. Semina: Ciências Agrárias, Londrina, v. 29, n. 1, p. 53-68, jan./mar. 2008.

CONCEIÇÃO, P. C; AMADO, T. J. C; MIELNICZUK, J; SPAGNOLLO, E. Qualidade do solo em sistemas de manejo avaliada pela dinâmica da matéria orgânica e atributos relacionados. Rev. Bras. Ciênc. Solo. v.29. n.5, p.777-788, 2005. 
SCHUMACHER, M. V. Aspectos da ciclagem de nutrientes e do microclima em talhões de Eucalyptus camaldulensis Dehnh, Eucalyptus grandis Hill ex Maiden e Eucalyptus torrelliana F. Mesell. 1992. 87f. Dissertação (Mestrado em Engenharia Florestal) - Escola Superior de Agricultura “Luiz de Queiroz”, Piracicaba, 1992.

TAN, Z; LAL, R; OWENS, L; IZAURRALDE R. C. Distribution of light and heavy fractions of soil organic carbon as related to land use and tillage practice. Soil Tillage Ress, v. 92 p. 53-59, 2007. 